\section{Endoscopic Submucosal Dissection Sociedad Española de Endoscopia Digestiva (SEED) clinical guideline}

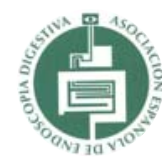

2. Barrett's associated adenocarcinoma: indications of ESD in this group of patients can be divided in 3 groups:

a) Absolute: HGD or intramucosal adenocarcinoma up to $\mathrm{m} 2$ and lesions bigger than

$20 \mathrm{~mm}$ but involving less of $2 / 3$ of the circumference of the esophagus.

b) Relative: adenocarcinoma $\mathrm{m} 3$ or sm1 without evidence of lymph node metastasis, or lesion with HGD or $\mathrm{m} 2$ involving less than $2 / 3$ of the circumference.

c) Experimental: lesions with sm2 invasion or deeper in high surgical risk patients.

Institutions

Institutions are listed at the end of article.

\section{Introduction}

$\nabla$

Endoscopic submucosal dissection (ESD) was developed in Japan as a treatment for early gastric cancer (EGC). This technique allows en-bloc resection of the lesions [1] which has demonstrated to be crucial because the local recurrence rate when this is not possible is of $15 \%$ [2]. Nowadays, there is a huge experience with ESD in Eastern countries where this technique is considered the gold standard treatment for EGC $[3,4]$. Indications for ESD have expanded to lesions in other locations (esophagus and colon) and other types of lesions (submucosal tumors). However, the introduction of ESD in Europe and the United States of America has been and still is very slow. The aim of this guideline is to familiarize Spanish endoscopists and gastroenterologists not only with the general indications of the procedure and possilble complications but also the dedicated tools.

\section{Indications}

$\nabla$

The main objective of ESD is the complete resection of neoplastic lesions to achieve the patient's cure. For this reason, the main indication is superficial lesions with no risk of lymphatic invasion. The risk of metastatic lymph nodes is determined by several factors related to neoplasia, such as cell type and degree of differentiation, size, presence of ulceration, lymphatic and / or vascular invasion and depth of wall invasion. According to the TNM classification [5, 6], early neoplasia of gastrointestinal tract is located in the mucosa and submucosa layers, but when the submucosa is affected the risk of lymphatic invasion increases up to $22 \%$.

\section{Esophagus}

Barrett's esophagus associated adenocarcinoma represents $50 \%$ of all the esophageal tumors [7,8]. By contrast, in Asia and Eastern Africa the epidermoid carcinoma is the histological predominant type [9]. ESD has different indications according to the histological type of the tumor to treat [10-12]:

1. Squamous carcinoma: resection of lesions with a major diameter bigger than $15 \mathrm{~mm}$, in any location and with rates of resection in block of the EMR are similar to those of the ESD. In lesions of more than $20 \mathrm{~mm}$, cure rate, absence of local recurrence and disease-free survival of ESD reach $99 \%$ and are superior to those of the fragmented EMR. On the other hand, the incident of perforation is $2.4 \%$ and not significantly different from RME $(1,7 \%)[13,14]$. Due to an incidence of lymph nodes metastasis of $8.5 \%$ when the carcinoma is $\mathrm{m} 3$ (affectation of the muscularis mucosae without affectation of the submucousal layer), endoscopic treatment should be indicated only for $\mathrm{m} 1$ and $\mathrm{m} 2$ lesions [14] in which the mortality for total esophagectomy ( $2 \%$ ) is equal or superior to the risk of metastasis, without difference in the long-term survival between the endoscopic and surgical treatment $[5,6,15]$. any size. For lesions of minor size, the
Finally, the risk of new areas of adenocarcinoma in the residual Barrett's esophagus forces to perform an ablative treatment of the rest of the metaplastic mucosa by means of either EMR or radio frequency [16].

\section{Recommendations:}

- Endoscopic resection is the best method for staging superficial neoplasms of the esophagus, At the same time it diminishes the rates of esophagectomy and offers a safe and effective treatment to these patients. Level of evidence $2++$. Grade of recommendation $B$.

- In general, endoscopic treatment of esophageal superficial neoplasms is indicated in T1 s and T1a tumors with no difference in the long-term survival between the endoscopic and the surgical treatment. Level of evidence $1+$. Grade of recommendation $A$.

- For esophageal squamous carcinoma less than $15 \mathrm{~mm}$ the rates of en-bloc resection of EMR are similar to ESD with a null recurrence rate. Level of evidence $2++$. Grade of recommendation $B$.

- Contrarily, for squamous carcinoma bigger than $20 \mathrm{~mm}$, the cure rate for ESD is superior to EMR. Level of evidence $2++$. Grade of recommendation $B$.

- In squamous carcinoma, due to an increased risk of lymph node metastasis in $\mathrm{m} 3$ lesions, endoscopic treatment should be indicated only for $m 1$ and $m 2$ lesions. Level of evidence 2+. Grade of recommendation $C$.

- In Barrett's esophagus with superficial adenocarcinoma, ESD is indicated in lesions greater than $20 \mathrm{~mm}$ with HGD, carcinoma in situ or invasive carcinoma up to m2. ESD may be indicated in patients with high surgical risk and invasive adenocarcinoma affecting the first third of submucosal layer (sm1 = 
Table 1 Summary of current indications of Endoscopic Submucosal Dissection in Early Gastric Cancer.

$\begin{array}{ll}\begin{array}{l}\text { Classic } \\ \text { indications }\end{array} & \begin{array}{l}\text { 1. Differentiated type early gastric cancer } \\ \text { 2. Elevated type lesions }<20 \mathrm{~mm}\end{array} \\ \begin{array}{l}\text { Expanded } \\ \text { indications }\end{array} & \begin{array}{l}\text { 1. Intramucosal cancer of any size with no ulcer and no lymphovascular } \\ \text { involvement }\end{array} \\ & \begin{array}{l}\text { 2. Intramucosal cancer, less than } 3 \mathrm{~cm} \text { in size, no lymphovascular } \\ \text { involvement, with or without ulcer }\end{array} \\ \begin{array}{l}\text { 3. Intestinal type cancer with submucosal invasion ( } \mathrm{sm} 1<500 \mathrm{um} \text { ), with size } \\ \text { less than } 3 \mathrm{~cm} \text { and without lymphovascular involvement }\end{array} \\ \begin{array}{l}\text { 4. Poorly differentiated type cancer, less than } 2 \mathrm{~cm} \text { in size, no ulcer }\end{array}\end{array}$

$500 \mu \mathrm{m})$. Level of evidence $2+$ Grade of recommendation $C$.

- In western countries, for Barrett's esophagus associated superficial neoplasms the results of ESD are similar to EMR. Therefore, the choice of the preferred treatment should be based on size of the lesion and the suspicion of invasion of the first third of the submucosal layer. Level of evidence $2++$. Grade of recommendation $B$.

- The risk of new areas of adenocarcinoma in the residual Barrett's esophagus forces to realize an ablative treatment of the rest of the metaplastic mucosa by means of either EMR or radiofrequency. Level of evidence $2++$. Grade of recommendation $B$.

\section{Stomach}

EGC is defined as cancer limited to the mucosa or submucosa irrespective of lymphnode metastasis [17], having an excellent prognosis after gastrectomy with lyphadenectomy with a 5-year survival rate of more than $90 \%[18,19]$. The incidence of lymphnode metastasis in early gastric cancer is very low when such cancer is limited to the mucosal layer (3\%), however, when cancer invades the submucosal layer it can increase up to $20 \%$ [20]. Consequently, local and a less invasive treatment than surgery would be indicated in those gastric cancers limited to the mucosa. The purpose of establishing indication criteria for ESD in gastric neoplasms is to ensure curative resection by complete removal of the tumor. Generally, an endoscopic resection is considered curative (minimal risk of lymphnode metastasis) when submucosal invasion is limited to $500 \mu \mathrm{m}$ in depth. There are several morphologic features of the lesions (macroscopic classification, mucosal and vascular patterns), which can enable us to predict the risk of invasion in depth. The indications for endoscopic resection of early gastric cancer traditionally established in Japan are ( $\bullet$ Table 1$)$ : well differ- entiated adenocarcinoma, lesion size $<2 \mathrm{~cm}$ if it is an elevated lesion or $<1 \mathrm{~cm}$ if depressed, without ulcer [17]. Nevertheless, such criteria has been extended to lesions of larger size, with ulcer $[21,22]$ and recently to undifferentiated type adenocarcinoma [23-26]. However, the number of patients that fulfil such criteria and have lymph node metastasis is higher than $12 \%$, explaining the reported poor results. [27]. Regarding prognostic factors, in a study of 487 gastric cancers endoscopically resected, several features were identified as associated with no curative resection: lesion size $(>3 \mathrm{~cm})$, with ulcer and histopathology (diffuse type or mixed type of Lauren classification) [28]. The risk of no curative resection is $<10 \%$ in lesions with no ulcer, $<3 \mathrm{~cm}$ in diameter and localized in the antrum and gastric body. However, such risk is $>40 \%$ in lesions with no ulcer, $>3 \mathrm{~cm}$ and localized in the fornix as well as in lesions with ulcer, size larger than $3 \mathrm{~cm}$ located anywhere or size $<3 \mathrm{~cm}$ located in the fornix. In such cases, surgical treatment is indicated [29].

Contraindications: Advanced age does not seem a contraindication [30,31]. Data regarding the risk of bleeding in patients who do not discontinue the use of antiplatelet drugs before ESD is controversial $[32,33]$. In cases with high risk of thrombotic disease, the necessity to continue treatment with such agents should not be a contraindication for the procedure [32].

\section{Recommendations:}

- In a well differentiated type EGC, ESD is the first therapeutic option irrespective of size and location of the lesion. Evidence level $1++$. Grade of Recommendation $A$.

- Size $>3 \mathrm{~cm}$, with ulcer and fornix location are associated with a higher rate of no curative resection. Evidence level $2+$. Grade of Recommendation $C$.
- Advanced age is no contraindication for ESD. Evidence level 2+. Grade of Recommendation $C$.

- In cases with high risk of thrombotic disease, treatment with antiplatelet drugs should not be considered a contraindication for ESD. Evidence level 2-. Grade of Recommendation $C$.

\section{Colon and rectum}

The macroscopic features of colonic lesions are established by their type according to the updated Paris classification [34] that includes the lateral spreading tumours (LSTs) described by Kudo [35]. This classification has a prognostic value as the risk of lymph node invasion in the colon varies depending on the macroscopic type of lesion. In sessile and flat lesions resection is considered curative when invasion into the submucosa is below $1.000 \mu \mathrm{m}$ due to the low risk of lymph node metastasis [36,37], while in pedunculated lesions the limit is more flexible leading to the combination of two parameters: invasion into the submucosa of up to $2.000 \mu \mathrm{m}[38,39]$ and a maximum diameter of invasion into the submucosa of up to $4.000 \mu \mathrm{m}>$ [38]. Lesions considered amenable to endoscopic treatment in general include ( Table 2): 1) lesions of any macroscopic type, 2) adenomas, intramucosal neoplasias or neoplasias with superficial submucosal infiltration, 3) lesions under $2 \mathrm{~cm}$ in maximum diameter [40]. Specific indications for ESD include [41] lesions with a high risk of adenocarcinoma or those presenting an additional difficulty for endoscopic resection.

Incidence and risk of submucosal invasion are higher for non-granular LSTs (LSTNG). ESD would be indicated in lesions of this kind that are larger than $2 \mathrm{~cm}$. Granular LSTs with nodules (LST-G mixed) present a higher risk of containing adenocarcinoma under the larger nodule and under pseudodepressed areas. In those cases, the larger nodule should be resected in a single piece or, for larger lesions, the whole lesion should be resected en bloc. Saito et al. consider ESD indicated in LST$\mathrm{G}$ mixed larger than $3 \mathrm{~cm}$ [42]. Other indications for ESD include mucosal lesions with submucosal fibrosis secondary to prior resections, biopsies or associated with inflammatory bowel disease [43]. In those cases, the risk of perforation or leaving a residual lesion is higher if ESD is not performed. Adding adrenaline to the submucosal injection solution could decrease the incidence of early bleeding of sessile and pedunculated polyps less than $1 \mathrm{~cm}$ 
Table 2 Indications of Endoscopic Submucosal Dissection for colorectal tumors

1. Large sized (>20 mm in diameter) lesions in which en bloc resection using a snare EMR is difficult, although it is indicative for endoscopic treatment

a) LST-NG particularly those of the pseudo-depressed type

b) Lesions showing $V_{\text {, }}$ type pit pattern

c) Carcinoma with submucosal infiltration

d) Large and depressed type lesions

e) Large elevated lesion suspected to be a cancer*

2. Mucosal lesions with fibrosis caused by prior biopsy or peristalsis

3. Sporadic localized tumors in chronic inflammation eg ulcerative colitis

4. Local residual early carcinoma after endoscopic resection

Abbreviations: LST: Lateral spreading tumor. NG: No granular. Type Vi: Pattern V

irregular in the classificatión of Kudo (malignant lesion but with indication færndoscopic resection )

* Includes LST granular mixed (LST-G mix)

[44-46]. Endoscopic resection of large colonic lesions is much cheaper than surgical resection [47] and implies a maintained quality of life for patients that are only attained after 1 to 5 years of convalescence in patients who have undergone surgery $[48,49]$.

After ESD with en bloc resection of a large colonic lesion a follow-up colonoscopy is required within 3 to 6 months to review the scar and rule out residual lesion and within one year due to the risk of developing new adenomas [50].

\section{Recommendations:}

- ESD is indicated in LST-NG over $2 \mathrm{~cm}$. Evidence level 1+. Grade of recommendation $B$.

- Other indications for ESD include mucosal lesions with significant fibrosis secondary to prior biopsy or incomplete resection, neoplastic lesions associated to inflammatory bowel disease and residual superficial neoplastic lesions after endoscopic resection. Evidence level 2Grade of recommendation $D$.

- Adding adrenaline to the submucosal injection solution may help decrease the incidence of bleeding though it does not exclude the use of a technique to precisely coagulate visible vessels arising from the submucosa. Evidence level 1-. Grade of recommendation $B$.

- Endoscopic resection of large colonic lesions is several times cheaper than surgical resection and implies better quality of life maintenance. Evidence level $2++$. Grade of recommendation $B$.

- After ESD with en bloc resection of a large colonic lesion a follow up colonoscopy should be performed in 3 to 6 months to rule out residual lesion and in 12 months to rule out new adenomas. Evidence level $1++$. Grade of recommendation $A$.

\section{Other locations}

\section{Duodenum}

Duodenal lesions susceptible to endoscopic resection include premalignant lesions like adenomas, benign lesions (Brünner hyperplasia or lipoma), and submucosal lesions with malignant potential like neuroendocrine tumors (NET) or gastrointestinal stromal tumors (GIST) [51]. ESD in duodenum is a complicated procedure due to the existence of a very thin submucosal layer, its high vascularity and also the presence of a thin muscular layer. All these factors increase the risk of bleeding and perforation, being this last reported up to $20 \%$ or even more [52]. There is no standardization relating to the size of lesions susceptible to treatment. Benefits of duodenal ESD seem marginal compared to EMR, with the exception of small-medium size encapsulated submucosal tumors (NET, for example), in which endoscopic ultrasound (EUS) has excluded muscular propia layer infiltration or locoregional lymph nodes involvement. The most frequent complication is bleeding [53]. It is important to perform preventive vessel coagulation with coagulation forceps, argon plasma or bipolar catheter. On the other hand, it is mandatory to perform a close surveillance to detect perforation, both acute or delayed. Delayed perforation has been associated with excessive use of electrocoagulation for achieving hemostasis and continuous exposure of the scar to pancreatic juice and bile [54]. Perforation rate is unacceptable high in some studies, reaching $36 \%$ of the patients.

\section{Recommendations:}

- Due to high complication rates (bleeding, perforation), duodenal ESD must be performed by highly experienced ESD endoscopists. Evidence level 3. Grade of recommendation $D$.
Mesopharynx and hipopharynx

ESD can be adequate for the diagnosis and treatment of early superficial neoplastic lesion in these locations [55,56]. ESD in this location should be performed by highly experienced endoscopists in ESD. To do a precise delimitation of the lesion an iodine instillation can be useful. This exploration must be performed under orotracheal intubation to avoid respiratory complications. Supine patient position could be useful because it enlarges the space for endoscopy manoeuvres due to maximum larynx elevation.

\section{Recommendations:}

- Superficial meso- and hipopharynx tumors can be treated by ESD. These explorations must be performed under orotracheal intubation. Supine patient position can facilitate the procedure. Level of evidence 3. Grade of recommendation $D$.

\section{Submucosal tumors}

The origin of these lesions in muscular propia layer is not a factor to preclude ESD, but perforation rates in this situation are higher. Average tumor size of resected specimens in various studies is around 20-30 mm maximum and a majority of them are GIST with low grade dysplasia, followed by leiomiomas and NETs. All referred resections were performed in upper digestive tube (esophagus, stomach and cardias), with R0 rates around 95$100 \%$ in the longest series. The technique is not standardized, and is described as the use of submucosal tunnel for resection of esophageal and cardiac lesions [57]. There has also been published resections of small rectal carcinoids ( $<10 \mathrm{~mm}$ ) without muscular propia involvement [58].

\section{Recommendations:}

- Submucosal lesions araising from muscular propia layer could be resected using ESD, especially those with a diameter $<30 \mathrm{~mm}$. Level of evidence 3. Grade of recommendation $D$.

- Esophageal or cardial submucosal lesions can be accessed performing $a$ submucosal tunnel. Level of evidence 3. Grade of recommendation $D$.

\section{Equipment}

\section{Knives}

The conventional ESD technique requires the use of different knives specific for each step of the procedure [59].The differ- 
Table 3 Characteristics of different knifes for endoscopic submucosal dissection.

\begin{tabular}{|c|c|c|c|c|c|c|c|}
\hline Device & Marking & Pre-cut & Cutting & Dissection & Hemostasis & Fibrosis & Beginners \\
\hline Needle Knife & $\checkmark$ & $\checkmark$ & $\checkmark$ & $\checkmark$ & $x$ & $\checkmark$ & $X$ \\
\hline Flex Knife & $\checkmark$ & $\checkmark$ & $\checkmark$ & $\checkmark$ & $x^{2}$ & $x$ & $\checkmark$ \\
\hline Hook Knife & $\sqrt{ }^{1}$ & $\checkmark$ & $\checkmark$ & $\checkmark$ & $x^{2}$ & $\checkmark$ & $x$ \\
\hline IT Knife & $x$ & $x$ & $\checkmark$ & $\checkmark$ & $x^{2}$ & $x$ & $\checkmark$ \\
\hline Triangle-tip Knife & $\sqrt{ }^{1}$ & $\checkmark$ & $\checkmark$ & $\checkmark$ & $x^{2}$ & $x$ & $\sqrt{ }^{3}$ \\
\hline Dual Knife & $\checkmark^{1}$ & $\checkmark$ & $\checkmark$ & $\checkmark$ & $x^{2}$ & $x$ & $\checkmark$ \\
\hline Hybrid Knife & $\checkmark$ & $\checkmark$ & $\checkmark$ & $\checkmark$ & $x^{2}$ & $\checkmark$ & $\checkmark$ \\
\hline
\end{tabular}

$\checkmark$ Suitable.

X Not recommended.

${ }^{1}$ They can be used for pre-cut with the tip fully retracted.

2 Useful for coagulation in case of venous bleeding, low flow, or bleeding from small vessels of $1 \mathrm{~mm}$.

${ }^{3}$ Difficult to use in fundus and body.

ent knives for ESD share a common structure: they are plastic catheters with a metallic tip that varies among different models. The vast majority of endoscopic knives is monopolar. Its area of contact with the tissue determines the cutting characteristics of the knife. A knife with a small contact area usually produces a deep cut because it generates a high current density [60].

According to the function they perform, knives can be classified as: knives with cutting-clotting ability and knives with cutting-clotting and injection-wash ability. The latter allow the injection of liquid without exchanging needles, achieving a faster dissection and saving time.

Knives can also be classified as covered (with insulated tip) and not covered. Covered knives have a cutting surface which is partially protected by insulating material, a design aimed at restricting the direction of the cut in order to make dissection maneuvers safer [60]. Not covered knives show their cutting area without restrictions and they usually have a retractable metallic tip of variable length. A clear superiority of a design versus the other has not been proven [61]. In 0 Table 3 the characteristics of the most used knives are detailed.

\section{Recommendations:}

- The choice of surgical knife depends on personal preferences and the familiarity with the available material. An objective superiority of one design over the rest has not been demonstrated. Level of evidence 2 -. Grade of recommendation $D$.

- There are no differences between the needle-knife and the IT-knife regarding precision or incidence of complications. Level of evidence 2 -. Grade of recommendation $D$.

- The use of a hook-knife is especially indicated when confronting fibrous lesions that prevent an appropriate distension of the submucous layer. Level of evidence 2 -. Grade of recommendation $D$.

- The use of a hybrid knife could facilitate the ESD procedure by shortening procedure time and diminishing complications. Level of evidence $2++$. Grade of recommendation $C$.

- Utilizing a transparent cap attached to the tip of the endoscope is recommended, as it allows the resection to be performed more safely and with better control. Level of evidence 4. Grade of recommendation $D$.

\section{Injection Substances}

In ESD, submucosal injection creates a cushion beneath the lesion and raises the submucosal layer, separating the mucosa from the muscularis propria [62,63]. Normal saline (NS) $0.9 \%$ maintains the cushion for a short time and usually makes it necessary to perform repeated injections during the dissection phase. Addition of epinephrine and/or colorants such as methylene blue or indigo carmine can facilitate resection by means of reducing the risk of bleeding and improving the identification of the submucosal layer. In order to prevent the short duration of submucosal injection effect, different substances with higher viscosity have been used [62-70]. Hyaluronic acid (HA) is one of the most commonly used substances in Japan but its high cost and in vitro tumor cells stimulatory effect, limit its use in other countries [63-67,71-74]. Glycerol or glycerin, is an hypertonic substance obtained from mixing 10\% glycerol and 5\% fructose. This substance is inexpensive and easily available at any center. It has proved higher durability and effectiveness than NS $0.9 \%[73,75]$. Fibrinogen has also been used in human studies [76]. There are many other solutions such as hypertonic (3\%) $\mathrm{NaCl}$, dextrose $(20,30,50 \%)$ and hydroxypropyl methylcellulose
(HPMC) (artificial tears) that have been used in an experimental setting. However, the description of tissue damage in experimental animals indicates that these solutions should be used with caution in humans [77-79]. Also on an experimental level, the use of promising substances with higher viscosity than NS $0.9 \%$ has been described. Some of them are autologous blood [69, 80], PS 137-25 (LeGooendoTM, Pluromed Inc, Woburn, USA) and 2-mercaptoethanol-sulfonate (mesna). The last one has a chemical effect that softens the submucosa connective tissue $[62-67,69,73,76,78,79,81]$.

\section{Recommendations:}

- NS $0.9 \%$ is a substance with little durability to maintain the submucosal cushion. The use of other substances with higher viscosity is recommended. Level of evidence $1+$. Grade of recommendation $A$.

- The use of NS $0.9 \%$ should be limited to cases where hydrodissection technique is used. Level of evidence 4. Grade of recommendation $D$.

- Hyaluronic acid is an ideal substance because of its viscosity, but its use is limited by its high cost, low availability in our environment and complains about its safety. Level of evidence $1++$. Grade of recommendation $A$.

- Glycerol $10 \%$ is a reasonable alternative because it is cheap and easily available in our environment. Level of evidence 1 +. Grade of recommendation A.

- Fibrinogen has a durability superior to NS $0.9 \%$ but its use is limited by its high price. Level of evidence $1+$. Grade of recommendation $B$.

- Dextrose is a reasonable and cheap alternative in Western countries but there are some concerns regarding its safety. Level of evidence 1-. Grade of recommendation $B$. 


\section{Electrosurgical generators}

Electrosurgical units generate a high frequency current that allows a cutting and/ or coagulation efect. This effect is due to the heat generated by the current running through the tissue, and depends on the different characteristics of the current (voltage, time, etc ) and on the tissue resistance.

When using high voltage continual currents $(>200 \mathrm{~V})$ a greater and continous heat delivery induces a cutting effect. Coagulation effect (without cell bursting leading to tissue desiccation and coagulation) could be achived both by low voltage currents or by interrupted high voltage currents.

The cut and coagulation effects could be used at the same time (blend effect), as every cutting effect associates some coagulation and every coagulation effect produces some cutting effect. [86]

New electrosurgery units have specific software that modulate the current and produces a specific tissue effect, for example the "endocut" mode from ERBE (ERBE, Tübingen, Germany). This mode induces tissue transection with continuous low voltage current followed by bursts of cutting current [87]. With this technique the tissue is first coagulated and then cut, with automatic cycles controlled by a microprocessor that take into account changes in the tissue electric resistance, and lead to a precise hemostasia and a safe cut.

\section{Recommendations}

- Endoscopists have to know the specific characteristics of the electrosurgical generator that they use, and be able to adjust the neccesary settings (mode, kind of current, power). Evidence level 4, Grade of recommendation $D$.

- The marking of the lesion margins is the first step for ESD, and soft coagulation current is used. Evidence level 4, Grade of recommendation $D$.

- A cutting current with coagulation effect is preferred for the initial circumferential incision, ideally with endocut feature or similar. Evidence level 4, Grade of recommendation $D$.

- For the dissection of the submucosa a coagulation current is usually advised for conventional knives; for the Hybrid Knife system (ERBE a mixed current with "endocut" mode is preferred. Evidence level 4, Grade of recommendation D.

- If hemostatic therapy is required, a soft coagulation mode or specific bipolar accesories are advised. Evidence level 4 Grade of recommendation $D$.

\section{Complications and postprocedure care \\ 7}

The two main complications of ESD procedure are hemorrhage and perforation. They are remarkable not only by their frequency but also because they can significantly affect the prognosis and therapeutic success of ESD $[88,89]$.

\section{Hemorrhage}

This complication may be classified as immediate (during the procedure) or delayed bleeding (within 2 weeks or later) [89]. The reported incidence of bleeding varies across the studies, depending on the location of the lesion. Thereby, the mean incidence is $2 \%$ in colorectal lesions, $9.3 \%$ in gastric lesions, and $0 \%-5.2 \%$ in the esophagus [90-93]. Immediate bleeding is considered clinically significant when any intervention apart from the endoscopic treatment is needed (i.e. urgent surgery, blood transfusions, vasopressor agents) or a drop in hemoglobin $\geq 2 \mathrm{~g} / \mathrm{dl}$ is detected [90,94]. Delayed bleeding is clinically relevant when there is a decrease of hemoglobin levels $\geq 2 \mathrm{~g} / \mathrm{dl}$, evidence of overt bleeding and endoscopic intervention is needed [94]. Up to $76 \%$ of delayed bleeding episodes take place within the first 24 hours after the procedure $[90,95]$. In gastric lesions an increased risk of bleeding has been reported when the lesions are located either in the middle or upper third of the stomach. Elderly patients ( $>80$ years), procedure time, size ( $\geq 40 \mathrm{~mm}$ ) and endoscopist experience have been also associated with an increased risk of bleeding [95-98]. Prevention and management of post-ESD bleeding

1. Endoscopic procedures: prophylactic electrocautery of large submucosal vessels during ESD has shown to decrease the risk of delayed bleeding up to $60 \%$ [99]. Performance of second-look after ESD is controversial [100]. Electrocautery rather than hemoclip placement is preferred for hemostasis because the latter may make the procedure cumbersome, preventing from continuing with the ESD [101]. Minor oozing can be treated by electrocautery with the same devices used for the ESD (i.e. IT knife, Flex knife...), whereas the hemostatic forceps (Coagrasper) are indicated in case of arterial bleeding.
2. Pharmacological treatment: only two randomized controlled trials have assessed the benefit of acid antisecretory drugs compared with no treatment prior to ESD in the prevention of delayed bleeding. None of them found differences between both strategies $[96,102]$. In terms of benefit after ESD, antisecretory drugs (PPIs) are usually recommended for 2 months in order to prevent delayed bleeding. In this setting, an 8-week treatment was found to be more effective than a 4-week treatment. However, ulcer healing rates at 4 or 8 weeks of treatment seem to be equivalent [103]. Recently, several randomized controlled trials compared the combination of PPI and mucosal protective agents (the most promising being rebamipide) with PPI monotherapy in the healing of iatrogenic ulcer after ESD. The use of PPI along with rebamipide might increase ulcer healing rates because of the synergic effect of both drugs [104-107]. Helicobacter pylori eradication had no impact on ulcer healing at 2 months follow-up after the procedure $[108,109]$. However, one study showed that Helicobacter pylori infection was a risk factor for ulcer recurrence after ESD [110]. Furthermore, it is well-known that Helicobacter pylori eradication reduces the incidence of metachronous gastric cancer and thereby, it is warranted in this setting [111].

\section{Perforation}

Perforation rate is around 5\% [90,91], although in less experienced Western series it increases up to 20\% (92-95). Observation of free extraluminal air after an ESD should not be always interpreted as a perforation leading to surgery. Mediastinal emphysema development has been described in a high percentage of patients undergoing esophageal ESD with no symptoms [112].

No recognition of the muscular layer during ESD can precipitate a perforation. Thus, the use of indigo carmine in the injection solution is advisable. It allows to clearly identify the bluish plane, meaning, the correct plane of dissection, thereby, making the procedure easier and safer. Depending on the perforation size and anatomical location, various sealing techniques may be applied such as clipping (simple closure or closure with omentum patch) or the insertion of a covered stent in cases of esophageal perforations [113]. 
After the endoscopic closure, the main care for patients includes fasting, intravenous fluid therapy and antibiotics with clinical and radiological surveillance. An average duration of two days for fasting in gastric perforations and 4-10 days in colonic perforations has been suggested. For colonic perforations, antibiotic therapy must be administered for 5 to 10 days $[114,115]$.

\section{Cicatricial stenosis}

This infrequent event is associated with large resections in gastric antrum or esophagus. Although dilation with bougienage or balloon have been extensively used, new therapeutic options have been described in order to prevent the development of stenosis, such as triamcinolone injection [116-118], preventive balloon dilation $[119,120]$ or oral steroids. In two non-randomized and retrospective studies, oral steroids alone or associated with balloon dilation were superior to endoscopic balloon dilation, reducing the number of dilations [121,122]. Other new treatments include biodegradable or metal stent insertion, topical application of mitomycin C or apposition of cell layers to prevent stricture formation [123-126]. Management of antral stenosis has been based on endoscopic balloon dilation, with a significant risk of perforation $[127,128]$. Finally, mucosal incision and local triamcinolone injection have been assayed [129].

\section{Other complications}

Other less frequent complications described in ESD are aspiration pneumonia, transient bacteremia [112], phlegmonous gastritis [130], gastric ischemia, gastric hematoma [131], transmural pneumatosis, deep vein thrombosis, mediastinal emphysema and tension pneumomediastinum or pneumoperitoneum [132135]. Peritoneal carcinomatosis is a rare complication and only one case has been published after gastric perforation. A retrospective series of 90 patients who underwent ESD with gastric perforation did not show this fearsome complication in the long-term.

\section{Recommendations:}

- Prophylactic treatment of large submucosal vessels during ESD decreases the risk of delayed bleeding and therefore it should be routinely performed. Evidence level $2++$. Grade of Recommendation $B$.

- Second-look after ESD contributes little to the prevention of delayed bleeding and therefore it should not be systema- tically recommended. Evidence level 1-. Grade of Recommendation $C$.

- Acid antisecretor agents administered before the procedure do not reduce the risk of delayed bleeding and are therefore not recommended. Evidence level 1-. Grade of Recommendation C.

- Proton pump inhibitors are superior to histamine- 2 receptor antagonists in prophylaxis of the delayed bleeding after ESD. Eight week administration of standard dosis of proton pump inhibitors is recommended. Evidence level $1+$. Grade of Recommendation A.

- Treatment with proton pump inhibitors is better than histamine-2 receptor antagonists in order to achieve ulcer healing. Level of evidence 1 -. Grade of Recommendation $B$.

- Clipping may prevent further contamination and reduce the risk of peritonitis, allowing conservative management of this complication. Evidence level 3. Grade of recommendation $D$.

- Two days of average duration of fasting in gastric perforations and 4-10 days in colonic perforations have been suggested. For colonic perforations, antibiotic therapy must be administered for 5-10 days. Evidence level 3. Grade of recommendation $D$.

- Triamcinolone injection (one or more sequential doses), applied for prevention of cicatricial stenosis, can achieve a reduction in the incidence of stricture and the need for additional treatment with balloon dilation. Evidence level 3. Grade of recommendation $D$.

- Preventive balloon dilation was effective and without adverse effects in two nonrandomized clinical trials. With this therapy, the objective is to prevent stenosis developed from the initial stages of wound healing by periodic dilations until the complete healing of the mucosa. Evidence level 3. Grade of recommendation D.

- Early treatment with oral prednisolone, starting at 2-3 days post-ESD and continued for 8 weeks, alone or associated with balloon dilation, is superior to endoscopic balloon dilation . Evidence level 3. Grade of recommendation $D$.

- Management of antral stenosis has been based on endoscopic balloon dilation, with a significant risk of perforation. Evidence level 3. Grade of recommendation $D$.

\section{Training in ESD \\ $\nabla$}

ESD is a complex and demanding technique. The skills required for ESD performance are commonly achieved after a long learning curve under expert's tutoring [136-137]. There are recommendations regarding training in $\mathrm{ESD}$, both in Asiatic and Western countries [138150]. Animal training under expert's supervision is essential, since it allows the trainee to overcome some of the limitations in learning ESD in real patients [150-151]. Some experts have proposed that the best way to set up a training program is to initiate procedures in the ex vivo porcine gastric model. After some practice, the trainee can move on to the in vivo animal model, where the endoscopist may experience a sense of reality of complications such as bleeding and perforation [151 - 153]. After having completed several gastric cases, the trainee may move to different locations: esophagus, rectum [148]. There are some encouraging reports which have shown that a high level of competence, with $100 \%$ enbloc resection rate, could be achieved by non-supervised Western endoscopists after completing 30 ESD cases in the ex vivo gastric animal model [154].

We should keep in mind that stepwise difficulty level, based on location and features of target lesions, seems to be mandatory. Not adhering to these principles may be associated with severe complications, which ultimately could be harmful for the patient and for the expansion of ESD [155].

\section{Recommendations:}

- Japanese experts recommend that for ESD training, the apprentice must have: 1) extensive knowledge in clinical care; 2) excellent skills for general endoscopic procedures: i.e. a) good experience in mucosal lesions assessment; $b$ ) nice ability for target biopsies; c) smooth cecal intubation technique; d) broad experience in hemostatic techniques, polypectomy and EMR. Level of evidence 4. Recommendation grade $D$.

- Endoscopists should be competent in gastric ESD before moving to colorectal ESD. Level of evidence 4. Recommendation grade $D$.

- Japanese experts have proposed a 4-step training strategy: 1) Initial stage: basic knowledge for detection and assessment of early gastric cancer, and awareness of ESD indications. 2) Second stage: Attend several ESD procedures performed by 
experts. 3) Third stage: Participate as assistant for an experienced endoscopist in ESD interventions; meanwhile, the trainee should initiate a training program in the animal model, ideally completing the first 30 cases within a year.

3) Fourth stage: Complete 30 gastric ESD under expert's supervision, preferably small, distal, and fibrosis and ulcer free lesions. Afterwards, 40 cases should be performed in proximal gastric locations. Finally, 40 colorectal ESD should be completed, preferably in the rectum during the initial training period. Level of evidence $2+$. Recommendation grade $C$.

- Japanese experts recommend a caseload of 30 colorectal ESDs for a level of competence in this location. Level of evidence 3. Recommendation grade $D$.

- In Europe, the recommended stepwise road map for ESD training would be as follows: 1) Essential knowledge of theory regarding diagnosis and treatment of early neoplasia in digestive tract.

2) Observation of ESD procedures performed by Asian experts.

3) Engagement in an animal training program under expert's supervision for basic skills acquisition. 4) Initiate selected human ESD cases supervised by experienced endoscopist. 5) Continued animal training for skill improvement. Level of evidence 3. Recommendation grade $D$.

- In Europe competence on ESD requires performing at least 10-20 every year. Level of evidence 4. Recommendation grade $D$.

- In Europe, a less exhaustive ESD training program than the one recommended by Japanese experts appears to be good enough to acquire basic competence on this technique. Level of evidence 2. Recommendation grade $D$.

\section{Institutions}

${ }^{1}$ Unidad de Endoscopia. Servicio de Gastroenterología. CIBEREHD. IDIBAPS. Hospital Clínic. Universidad de Barcelona. Barcelona

2 Unidad de Endoscopia. Servicio de Aparato Digestivo. Hospital de Basurto. Bilbao

3 Unidad de Endoscopia. Servicio de Aparato Digestivo. Hospital Universitario Marqués de Valdecilla. Hospital Virtual Valdecilla. Santander

${ }^{4}$ Servicio de Aparato Digestivo. Hospital Universitario 12 de Octubre. Madrid

${ }^{5}$ Unidad de Endoscopia. Servicio de Aparato Digestivo. Hospital Clínico San Carlos

${ }^{6}$ Servicio de Aparato Digestivo. Hospital Universitario de Canarias. La Laguna. Tenerife

7 Servicio de Digestivo. IDIPHIM. Hospital Universitario Puerta de Hierro Majadahonda. Universidad Autónoma de Madrid
Servicio de Aparato Digestivo. Complejo Hospitalario Universitario de Vigo

${ }^{9}$ Unidad de Endoscopia Digestiva. Servicio de Aparato Digestivo. Hospital General Universitario Gregorio Marañón

10 Unidad de Gestion Clinica de Digestivo. Hospital Clinico Universitario Virgen de la Arrixaca, Murcia

11 Unidad de Endoscopia. Servicio de Aparato Digestivo. Hospital de Galdakao-Usansolo. Bizkaia

12 Departamento de Gastroenterología. FacultaddeMedicina. Pontificia Universidad Católica de Chile. Santiago. Chile

${ }^{13}$ Complejo Hospitalario de Ourense.

14 Unidad de Aparato Digestivo. Hospital Costa del Sol. Marbella

15 Unidad de Endoscopia. Servicio de Gastroenterología. Hospital Universitario Ramón y Cajal. Madrid. Universidad de Alcalá, IRYCIS

16 Unidad de Endoscopia. Servicio de Aparato Digestivo. Complejo Hospitalario de Navarra. Pamplona

17 Servicio de Aparato Digestivo. Hospital Universitario Lucus Augusti. Lugo

\section{References}

1 Korenaga D, Haraguchi S, Tsujitani $S$ et al. Clinicopathological features of mucosal carcinoma of the stomach with lymph node metastasis in eleven patients. $\mathrm{Br} \mathrm{J}$ Surg 1986; 73: $431-433$

2 Tanabe S, Koizumi W, Higuchi Ket al. Clinical outcome of endoscopic aspiration mucosectomy for early stage gastric cancer. Gastrointest Endosc 2002; 56: 708-713

3 Rembacken BJ, Gotoda T, Fujii T et al. Endoscopic mucosal resection. Endoscopy 2001; 33: $709-718$

4 Soetikno RM, Gotoda T, Nakanishi Y et al. Endoscopic mucosal resection. Gastrointest Endosc 2003; 57: $567-579$

5 Edge SB, Byrd DR, Compton CC et al., eds. AJCC Cancer Staging Manual. 7 th ed. New York: Springer-Verlag; 2009: 103-115

6 The Japan Esophageal Society. Guide Lines of the Clinical and Pathologic Studies on Carcinoma of the esophagus. Tokyo: Kanehara; 2007

7 Muto M. Endoscopic diagnostic strategy of superficial esophageal squamous cell carcinoma. Digestive Endoscopy 2013; 25: 1 -6

8 Oyama T. Diagnostic strategies of superficial Barrett's esophageal cancer for endoscopic submucosal dissection. Digestive Endoscopy 2013; 25: 7-12

9 Parkin DM, Bray F, Ferlay J et al. Global cancer statistics, 2002. CA Cancer J Clin 2005; 55: 74-108

10 Shimizu Y, Takahashi M, Yoshida T et al. Endoscopic resection (endoscopic mucosal resection/endoscopic submucosal dissection) for superficial esophageal squamous cell carcinoma: Current status of various techniques. Digestive Endoscopy 2013; 25: 13 19

11 Koike T, Nakagawa K, Iijima $K$ et al. Endoscopic resection (endoscopic submucosaldissection/endoscopic mucosal resection) for superficial Barrett's esophageal cancer. Digestive Endoscopy 2013; 25: 20-28

12 Enestvedt BK, Ginsberg GG. Advances in Endoluminal Therapy for Esophageal Cancer. Gastrointest Endoscopy Clin N Am 2013; 23: $17-39$
13 Ishihara $R$, Iishi $H$, Uedo $N$ et al. Comparison of EMR and endoscopic submucosal dissection for en bloc resection of early esophageal cancers in Japan. Gastrointest Endosc 2008; 68: $1066-1072$

14 Takahashi $H$, Arimura $Y$, Masao $H$ et al. Endoscopic submucosal dissection is superior to conventional endoscopic resection as a curative treatment for early squamous cell carcinoma of the esophagus (with video). Gastrointest Endosc 2010; 72: 255-264

15 Westerterp M, Koppert LB, Buskens CJ et al. Outcome of surgical treatment for early adenocarcinoma of the esophagus or gastroesophageal junction. Virchows Arch 2005; 446: 497 - 504

16 van Vilsteren FGI, Alvarez Herrero L, Pouw RE et al. Predictive factors for initial treatment response after circumferential radiofrequency ablation for Barrett's esophagus with early neoplasia: a prospective multicenter study. Endoscopy 2013; 45: 516- 525

17 Japanese Gastric Cancer Association. Japanese classification of gastric carcinoma, 2nd English Ed. Gastric Cancer 1998; 1: 10-24

18 Committee of Photofluorography. Standardized method of gastric photofluorography (in Japanese). J Jpn Soc Gastroenterol. Mass Survey 1984; 62: 63

19 Okamura T, Tsujitani S, Korenaga $D$ et al. Lymphadenectomy for cure in patients with early gastric cancer and lymph node metastasis. Am J Surg 1988; 155: 476-480

20 Sasako M, Kinoshita T, Maruyama K. Prognosis of early gastric cancer (in Japanese with English abstract). Stomach Intestine 1993; 28: $139-146$

21 Gotoda $T$. Endoscopic resection of early gastric cancer. Gastric Cancer 2007; 10: 1 -11

22 Takenaka $R$, Kawahara Y, Okada $H$ et al. Risk factors associated with local recurrence of early gastric cancers after endoscopic submucosal dissection. Gastrointest Endosc 2008; 68: 887 -894

23 Kunisaki C, Shimada $H$, Nomura $M$ et al. Therapeutic strategy for signet ring cell carcinoma of the stomach. Br J Surg 2004; 91: 1319-1324

24 Park YD, Chung YJ, Chung HY et al. Factors related to lymph node metastasis and the feasibility of endoscopic mucosal resection for treating poorly differentiated adenocarcinoma of the stomach. Endoscopy 2008; 40: 7-10

25 Takizawa KST, Nakanishi Y, Taniguchi H et al. Expanded indication for endoscopic resection from the pathological viewpoint: the possibility of SM invasion by undifferentiated-type early gastric cancer. Stomach and Intestine 2006; 41: 9-17

26 Ye BD, Kim SG, Lee JY et al. Predictive factors for lymph node metastasis and endoscopic treatment strategies for undifferentiated early gastric cancer. J Gastroenterol Hepatol 2008; 23: $46-50$

27 Kang HJ, Kim DH, Jeon TY et al. Lymph node metastasis from intestinal-type early gastric cancer: experience in a single institution and reassessment of the extended criteria for endoscopic submucosal dissection. Gastrointest Endosc 2010; 72: 508 - 515

28 Lee TH, Cho JY, Chang YW et al. Appropriate indications for endoscopic submucosal dissection of early gastric cancer according to 
tumor size and histologic type. Gastrointest Endosc 2010; 71: $920-926$

29 Hirasawa K, Kokawa A, Oka $\mathrm{H}$ et al. Risk assessment chart for curability of early gastric cancer with endoscopic submucosal dissection. Gastrointest Endosc 2011; 74: 1268 1275

30 Tokioka S, Umegaki E, Murano M et al. Utility and problems of endoscopic submucosal dissection for early gastric cancer in elderly patients. Journal of Gastroenterology and Hepatology 2012; 27: 63-69

31 Abe N, Gotoda T, Hirasawa T et al. Multicenter study of the long-term outcomes of endoscopic submucosal dissection for early gastric cancer in patients 80 years of age or older. Gastric Cancer 2012; 15: 70 - 75

$32 \mathrm{Lim} \mathrm{JH,} \mathrm{Kim} \mathrm{SG,} \mathrm{Kim} \mathrm{JW.} \mathrm{Do} \mathrm{antiplatelets} \mathrm{in-}$ crease the risk of bleeding after endoscopic submucosal dissection of gastric neoplasms? Gastrointest Endosc 2012; 75: $719-727$

33 Cho SJ, Choi IJ, Kim CG et al. Aspirin use and bleeding risk after endoscopic submucosal dissection in patients with gastric neoplasms. Endoscopy 2012; 44: 114-121

34 Endoscopic Classification Review Group. Update on the paris classification of superficial neoplastic lesions in the digestive tract. Endoscopy 2005; 37: $570-578$

35 Kudo S. Endoscopic mucosal resection of flat and depressed early colorectal cancer. Endoscopy 1993; 25: 455-461

36 Fu K, Sano Y, Kato $S$ et al. Hazards of endoscopic biopsy for flat adenoma before endoscopic mucosal resection. Dig Dis Sci 2005 50: $1324-1327$

37 Kitajima K, Fujimori T, Fujii S et al. Correlations between lymph node metastasis and depth of submucosal invasion in submucosal invasive colorectal carcinoma: a Japanese collaborative study. J Gastroenterol 2004; 39: 534-543

38 Egashira Y, Yoshida T, Hirata I et al. Analysis of pathological risk factors for lymph node metastasis of submucosal invasive colon cancer. Mod Pathol 2004; 17: 503 - 511

39 Ueno H, Mochizuki H, Hashiguchi Y et al. Risk factors for an adverse outcome in early invasive colorectal carcinoma. Gastroenterol 2004; 127: 385 - 394

40 Watanabe T, Itabashi M, Shimada $Y$ et al. Japanese Society for Cancer of the Colon and Rectum (JSCCR) guidelines 2010 for the treatment of colorectal cancer. Int J Clin Oncol 2012; 17: 1 - 29

41 Tanaka S, Oka S, Kaneko I et al. Endoscopic submucosal dissection for colorectal neoplasia: possibility of standardization. Gastrointest Endosc 2007; 66: 100-107

42 Saito Y, Sakamoto T, Fukunaga S et al. Endoscopic submucosal dissection (ESD) for colorectal tumors. Dig Endosc 2009; 21: 7-12

43 Repici A, Hassan C, De Paula Pessoa D et al. Efficacy and safety of endoscopic submucosal dissection for colorectal neoplasia: a systematic review. Endoscopy 2012; 44: 137 150

44 Lee SH, Lee KS, Park YS et al. Submucosal saline-epinephrine injection in colon polypectomy: appropriate indication. Hepatogastroenterology 2008; 55: 1589-1593

45 Dobrowolski S, Dobosz M, Babicki A et al. Prophylactic submucosal saline-adrenaline injection in colonoscopic polypectomy: pro- spective randomized study. Surg Endosc 2004; 18: 990 - 993

46 Hsieh YH, Lin HJ, Tseng GY et al. Is submucosal epinephrine injection necessary before polypectomy? A prospective, comparative study Hepatogastroenterology 2001; 48: $1379-1382$

47 Onken JE, Friedman JY, Subramanian S et al. Treatment patterns and costs associated with sessile colorectal polyps. Am J Gastroenterol 2002; 97: 2896-2901

48 Caravati-Jouvenceaux A, Launoy G, Klein D et al. Health-related quality of life among longterm survivors of colorectal cancer: a population-based study. Oncologist 2011; 16 : $1626-1636$

49 Gall CA, Weller D, Esterman A et al. Patient satisfaction and health-related quality of life after treatment for colon cancer. Dis Colon Rectum 2007; 50: 801 -809

50 Arditi C, Gonvers JJ, Burnand B et al. Appropriateness of colonoscopy in Europe (EPAGE II); surveillance after polypectomy and after resection of colorectal cancer. Endoscopy 2009; 41: 209-217

51 Bourke MJ. Endoscopic resection in the duodenum: current limitations and future directions. Endoscopy 2013; 45: 127-132

$52 \mathrm{Kim} \mathrm{KO}$, Kim SJ, Kim TH et al. Do you have what it takes for challenging endoscopic submucosal dissection cases? World J Gastroenterol 2011; 17: 3580-3584

53 Lépilliez V, Chemaly M, Ponchon T et al. Endoscopic resection of sporadic duodenal adenomas: an efficient technique with a substantial risk of delayed bleeding. Endoscopy 2008; 40: $806-810$

54 Apel $D$, Jakobs $R$, Spiethoff $A$ et al. Follow-up after endoscopic snare resection of duodenal adenomas. Endoscopy 2005; 37: $444-$ 448

55 Shimizu Y, Yamamoto J, Kato $M$ et al. Endoscopic submucosal dissection for treatment of early stage hypopharyngeal carcinoma. Gastrointest Endosc 2006; 64: 255 - 259

56 Iizuka T, Kikuchi D, Hoteya $S$ et al. Clinical advantage of endoscopic submucosal dissection over endoscopic mucosal resection for early mesopharyngeal and hypopharyngeal cancers. Endoscopy 2011; 43: 839-843

57 Huang ZG, Zhang XS, Huang SL et al. Endoscopy dissection of small stromal tumors emerged from the muscularis propria in the upper gastrointestinal tract: Preliminary study. World J Gastrointest Endosc 2012; 4: 565 - 570

58 Onozato Y, Kakizaki S, Iizuka $\mathrm{H}$ et al. Endoscopic submucosal dissection for rectal carcinoid tumors. Dis Colon Rectum 2010; 53: $169-176$

59 Toyonaga T, Nishino E, Man $M$ et al. Principles of Quality Controlled Endoscopic Submucosal Dissection with Appropriate Dissection Level and High Quality Resected Specimen. Clin Endosc 2012; 45: 362 - 374

60 Matsui N, Akahoshi K, Nakamura K et al. Endoscopic submucosal dissection for removal of superficial gastrointestinal neoplasms: A technical review. World J Gastrointest Endosc 2012; 4: 123-136

61 Lee BI. Indications, Knives, and Electric Current: What's the Best? Clin Endosc 2012; 45: $285-287$

62 Rosenberg N, New Brunswick NJ. Submucosal saline wheal as safety factor in fulguration of rectal and sigmoidal polipy. Arch Surg 1955; 70: 120-122

63 Fujishiro $M$, Yahagi $N$, Kashimura $K$ et al. Comparison of various submucosal injection solutions for maintaining mucosal elevation during endoscopic mucosal resection. Endoscopy 2004; 36: 579-583

64 Giday SA, Magno P, Buscaglia JM et al. Is blood the ideal submucosal cushioning agent? A comparative study in a porcine model Endoscopy 2006; 38: 1230 - 1234

65 Yeh RW, Triadafilopoulos G. Submucosal injection: safety cushion at what cost? Gastrointest Endosc 2005; 62: 943 - 945

66 Conio M, Rajan E, Sorbi D et al. Comparative performance in the porcine esophagus of different solutions used for mucosal injection. Gastrointest Endosc 2002; 56: $513-$ 516

67 Hyun JJ, Chun HR, Chun HJ et al. Comparison of the characteristics of submucosal injection solutions used in endoscopic mucosal resection. Scand J Gastroenterol 2006; 41: $488-492$

68 Kantsevoy SV, Adler DG, Conway JD. ASGE technology committee. et al. Endoscopic mucosal resection and endoscopic submucosal dissection. Gastrointest Endosc 2008; 68: $11-8$

69 Matsui Y, Inomata M, Izumi K et al. Hyaluronic acid stimulates tumor-cell proliferation at wound sites. Gastrointest Endosc 2004; 60: $539-543$

70 Bures J, Kopácová M, Kvetina J et al. Different solutions used for submucosal injection influenced early healing of gastric endoscopic mucosal resection in a preclinical study in experimental pigs. Surg Endosc 2009; 23: 2094-2101

71 Yamamoto $H$, Yube $T$, Isoda $N$ et al. A novel method of endoscopic mucosal resection using sodium hyaluronate. Gastrointest Endosc 1999; 50: $251-256$

72 Lee SH, Cho WY, Kim HJ et al. A new method of EMR: submucosal injection of a fibrinogen mixture. Gastrointest Endosc 2004; 59 $220-224$

73 Uraoka T, Fujii T, Saito Yet al. Effectiveness of glycerol as a submucosal injection for EMR. Gastrointest Endosc 2005; 61: 736-740

74 http://www.vademecum.es/medicamentohyalgan_ficha_22180

75 Sumiyoshi T, Fuji TM, Sumiyoshi Yet al. Injected substances to the submucosa in endoscopic mucosal resection: glycerin solution versus normal saline solution [abstract]. Gastrointest Endosc 2002; 55: AB1 10

76 Lee SH, Park JH, Park doH et al. Clinical efficacy of EMR with submucosal injection of a fibrinogen mixture: a prospective randomized trial. Gastrointest Endosc 2006; 64: 691-696

77 Fujishiro M, Yahagi N, Kashimura K et al. Tissue damage of different submucosal injection solutions for EMR. Gastrointest Endosc 2005; 62: 933 - 942

78 Polymeros D, Kotsalidis G, Triantafyllou K et al. Comparative performance of novel solutions for submucosal injection in porcine stomachs: An ex vivo study. Dig Liv Dis 2010; 42: 226-229

79 Feitoza AB, Gostout CJ, Burgart LJ et al. Hydroxypropyl methylcellulose: a better submucosal fluid cushion for endoscopic muco- 
sal resection. Gastrointest Endosc 2003; 57: $41-47$

80 Sato T. A novel method of endoscopic mucosal resection assisted by submucosal injection of autologous blood (blood patch EMR). Dis Colon Rectum 2006; 49: 1636-41

81 Fernández-Esparrach G, Shaikh SN, Cohen A et al. Efficacy of a reverse-phase polymer as a submucosal injection solution for EMR: a comparative study (with video). Gastrointestinal Endoscopy 2009; 69: 1135 - 1139

82 Al Taie OH, Bauer Y, Dietrich CG et al. Efficacy of submucosal injection of different solutions inclusive blood components on mucosa elevation for endoscopic resection. Clin Exp Gastroenterol 2012; 5: 43-48

83 Lenz L, Di Sena V, Nakao FS et al. Hydroxipropyl methilcellulose, Carboxymethylcellulose and normal saline solution in a porcine model. Arq Gastroenterol 2010; 47: $184-$ 187

84 Katsinelos P, Kontouras J, Paroutoglou G et al. A comparative study of $50 \%$ dextrose and normal saline solution on their ability to create submucosal fluid cushions for endoscopic resection of sessile rectosigmoid polyps. Gastrointestinal Endoscopy 2008; 68: $692-698$

85 Park S, Chun HJ, Kim CY et al. Electrical characteristics of various submucosal injection fluids for endoscopic mucosal resection. Dig Dis Sci 2008; 53: $1678-1682$

86 Morris ML, Tucker RD, Baron TH et al. Electrosurgery in gastrointestinal endoscopy: principles to practice. Am J Gastroenterol 2009; 104: 1563 - 1574

87 Slivka A, Bosco JJ, Barkun AN et al. Technology Committee of the American Society for Gastrointestinal Endoscopy, USA Electrosurgical generators. Gastrointest Endosc 2003; 58: $656-660$

88 Toyokawa $T$, Inaba $T$, Omote $S$ et al. Risk factors for perforation and delayed bleeding associated with endoscopic submucosal dissection for early gastric neoplasms; analysis of 1123 lesions. J Gastroenterol Hepatol 2012; 27: 907-912

89 Gotoda T, Yamamoto H, Soetikno RM. Endoscopic submucosal dissection of early gastric cancer. J Gastroenterol 2006; 41: 929-942

90 Oda I, Gotoda T, Hamanaka $\mathrm{H}$ et al. Endoscopic submucosal dissection for early gastric cancer. Technical feasibility, operation time and complications from a large consecutive series. Digestive Endoscopy 2005; 17: $54-58$

91 Lian J, Chen S, Zhang $Y$ et al. A meta-analysis of endoscopic submucosal dissection and EMR for early gastric cancer. Gastrointest Endosc 2012; 76: 763 - 770

92 Repici A, Hassan C, De Paula Pessoa D et al. Efficacy and safety of endoscopic submucosal dissection for colorectal neoplasia: a systematic review. Endoscopy 2012; 44: 137 150

93 Isomoto $H$, Yamaguchi $N$, Minami $H$ et al. Management of complications associated with endoscopic submucosal dissection/ endoscopic mucosal resection for esophageal cancer. Dig Endosc 2013; 25: 29-38

94 Tajiri H, Kitano S. Complications associated with endoscopic mucosal resection: Definition of bleeding that can be viewed as accidental. Digestive Endoscopy 2004; 16: 134 136
95 Toyokawa T, Inaba T, Omote $S$ et al. Risk factors for perforation and delayed bleeding associated with endoscopic submucosal dissection for early gastric neoplasms: analysis of 1123 lesions. J Gastroenterol Hepatol 2012; 27: 907-912

96 Watanabe $Y$, Kato $N$, Maehata T et al. Safer endoscopic gastric mucosal resection: preoperative proton pump inhibitor administration. J Gastroenterol Hepatol 2006; 21: $1675-1680$

97 Okada K, Yamamoto Y, Kasuga A et al. Risk factors for delayed bleeding after endoscopic submucosal dissection for gastric neoplasm. Surg Endosc 2011; 25: 98 - 107

98 Jeon SW, Jung MK, Cho CM et al. Predictors of immediate bleeding during endoscopic submucosal dissection in gastric lesions. Surg Endosc 2009; 23: 1974-1979

99 Takizawa K, Oda I, Gotoda T et al. Routine coagulation of visible vessels may prevent delayed bleeding after endoscopic submucosal dissection - an analysis of risk factors. Endoscopy 2008; 40: 179-183

100 Ryu HY, Kim JW, Kim HS et al. Second-look endoscopy is not associated with better clinical outcomes after gastric endoscopic submucosal dissection: a prospective, randomized, clinical trial analyzed on an astreated basis. Gastrointest Endosc 2013; 78: $285-294$

101 Muraki Y, Enomoto S, Iguchi M et al. Management of bleeding and artificial gastric ulcers associated with endoscopic submucosal dissection. World J Gastrointest Endosc 2012; 4: 1-8

102 Ono S, Kato M, Ono $Y$ et al. Effects of preoperative administration of omeprazole on bleeding after endoscopic submucosal dissection: a prospective randomized controlled trial. Endoscopy 2009; 41: 299 303

103 Yang Z, Wu Q Liu Z et al. Proton pump inhibitors versus histamine-2-receptor antagonists for the management of iatrogenic gastric ulcer after endoscopic mucosal resection or endoscopic submucosal dissection: a meta-analysis of randomized trials. Digestion 2011; 84: 315-320

104 Fujiwara S, Morita Y, Toyonaga $T$ et al. A randomized controlled trial of rebamipide plus rabeprazole for the healing of artificial ulcers after endoscopic submucosal dissection. J Gastroenterol 2011; 46: 595-602

105 Kato T, Araki H, Onogi $F$ et al. Clinical trial: rebamipide promotes gastric ulcer healing by proton pump inhibitor after endoscopic submucosal dissection-a randomized controlled study. J Gastroenterol 2010; 45: 285-290

106 Kobayashi Y, Kudo SE, Miyachi $H$ et al. Clinical usefulness of pit patterns for detecting colonic lesions requiring surgical treatment. Int J Colorectal Dis 2011; 26: 1531 1540

107 Shin WG, Kim SJ, Choi MH et al. Can rebamipide and proton pump inhibitor combination therapy promote the healing of endoscopic submucosal dissection-induced ulcers? A randomized, prospective, multicenter study Gastrointest Endosc 2012; 75: 739-747

108 Kakushima N, Fujishiro M, Yahagi $N$ et al. Helicobacter pylori status and the extent of gastric atrophy do not affect ulcer heal- ing after endoscopic submucosal dissection. J Gastroenterol Hepatol 2006; 21 : $1586-1589$

109 Ueda H, Ito M, Tanaka $S$ et al. The effect of Helicobacter pylori eradication therapy on gastric ulcer healing after endoscopic mucosal resection. J Clin Gastroenterol 2006; 40: $293-296$

110 Huang $Y$, Kakushima N, Takizawa $K$ et al. Risk factors for recurrence of artificial gastric ulcers after endoscopic submucosal dissection. Endoscopy 2011; 43: 236-239

111 Fukase K, Kato M, Kikuchi S et al. Effect of eradication of Helicobacter pylori on incidence of metachronous gastric carcinoma after endoscopic resection of early gastric cancer: an open-label, randomised controlled trial. Lancet 2008; 372: $392-397$

112 Maeda Y, Hirasawa D, Fujita $N$ et al. Mediastinal emphysema after esophageal endoscopic submucosal dissection: its prevalence and clinical significance. Dig Endosc 2011; 23: $221-226$

113 Oda I, Suzuki H, Nonaka S et al. Complications of gastric endoscopic submucosal dissection. Dig Endosc 2013; 25: 71 - 78

114 Taku K, Sano Y, Fu KI et al. Iatrogenic perforation associated with therapeutic colonoscopy: a multicenter study in Japan. J Gastroenterol Hepatol 2007; 22: 14091414

115 Minami S, Gotoda T, Ono H et al. Complete endoscopic closure of gastric perforation induced by endoscopic resection of early gastric cancer using endoclips can prevent surgery (with video). Gastrointest Endosc 2006; 63: 596-601

116 Isomoto $\mathrm{H}$, Yamaguchi $\mathrm{N}$, Minami $\mathrm{H}$ et al. Management of complications associated with endoscopic submucosal dissection endoscopic mucosal resection for esophageal cancer. Dig Endosc 2013; 25: 29-38

117 Hashimoto S, Kobayashi M, Takeuchi M et al. The efficacy of endoscopic triamcinolone injection for the prevention of esophageal stricture after endoscopic submucosal dissection. Gastrointest Endosc 2011; 74: $1389-1393$

118 Hanaoka N, Ishihara R, Takeuchi Y et al. Intralesional steroid injection to prevent stricture after endoscopic submucosal dissection for esophageal cancer: a controlled prospective study. Endoscopy 2012; 44: 1007-1011

119 Wang C, Lu X, Chen P. Clinical value of preventive balloon dilatation for esophageal stricture. Exp Ther Med 2013; 5: 292 - 294

120 Ezoe $Y$, Muto M, Horimatsu T et al. Efficacy of preventive endoscopic balloon dilation for esophageal stricture after endoscopic resection. J Clin Gastroenterol 2011; 45: 222-227

121 Yamaguchi N, Isomoto H, Nakayama T et al. Usefulness of oral prednisolone in the treatment of esophageal stricture after endoscopic submucosal dissection for superficial esophageal squamous cell carcinoma. Gastrointest Endosc 2011: 73: 1115 - 1121

122 Sato H, Inoue H, Kobayashi $Y$ et al. Control of severe strictures after circumferential endoscopic submucosal dissection for esophageal carcinoma: oral steroid therapy with balloon dilation or balloon dilation alone. Gastrointest Endosc 2013; 78: 250-257 
123 Machida H, Tominaga K, Minamino $\mathrm{H}$ et al. Locoregional mitomycin $\mathrm{C}$ injection for esophageal stricture after endoscopic submucosal dissection. Endoscopy 2012; 44: $622-625$

124 Ohki T, Yamato M, Ota M et al. Prevention of esophageal stricture after endoscopic submucosal dissection using tissue-engineered cell sheets. Gastroenterology 2012; 143: $582-588$ e1-2.

125 Matsumoto S, Miyatani H, Yoshida $Y$ et al. Cicatricial stenosis after endoscopic submucosal dissection of esophageal cancer effectively treated with a temporary selfexpandable metal stent. Gastrointest Endosc 2011; 73: 1309-1312

126 Saito Y, Tanaka T, Andoh A et al. Novel biodegradable stents for benign esophageal strictures following endoscopic submucosal dissection. Dig Dis Sci 2008; 53: $330-$ 333

127 Coda S, Oda I, Gotoda $T$ et al. Risk factors for cardiac and pyloric stenosis after endoscopic submucosal dissection, and efficacy of endoscopic balloon dilation treatment. Endoscopy 2009; 41: 421-426

128 Tsunada S, Ogata S, Mannen K et al. Case series of endoscopic balloon dilation to treat a stricture caused by circumferential resection of the gastric antrum by endoscopic submucosal dissection. Gastrointest Endosc 2008; 67: 979-983

129 Mori H, Kobara H, Fujihara S et al. Recanalization of severe gastric antral stricture after large endoscopic submucosal dissection: mucosal incision and local steroid injection. J Gastrointestin Liver Dis 2012; 21: 435-437

130 Ajibe H, Osawa H, Yoshizawa M et al. Phlegmonous Gastritis after Endoscopic Submucosal Dissection for early Gastric Cancer. Therap Adv Gastroenterol 2008; 1: 91 -95

131 Yang $C W$, Yen $H H$. Large gastric intramural hematoma: unusual complication of endoscopic submucosal dissection. Endoscopy 2011; 43: E240

132 Hyun YS, Han DS, Lee HL et al. Gastric emphysema after endoscopic submucosal dissection. Endoscopy 2011; 43: E83-4

133 Kusunoki M, Miyake K, Shindo $T$ et al. The incidence of deep vein thrombosis in Japanese patients undergoing endoscopic submucosal dissection. Gastrointest Endosc 2011; 74: 798-804

134 Tamiya $Y$, Nakahara $K$, Kominato $K$ et al. Pneumomediastinum is a frequent but minor complication during esophageal endoscopic submucosal dissection. Endoscopy $2010 ; 42: 8-14$

135 Siboni $S$, Bona $D$, Abate $E$ et al. Tension pneumoperitoneum following endoscopic submucosal dissection of leiomyoma of the cardia. Endoscopy 2010; 42: E152

136 Gotoda T, Yamamoto H, Soetikno RM. Endoscopic submucosal dissection of early gastric cancer. J Gastroenterol 2006; 41: 929-942

137 Kakushima N, Fujishiro M, Kodashima $S$ et al. A learning curve for endoscopic submucosal dissection of gastric epithelial neoplasms. Endoscopy 2006; 38: 991 -995

138 Fujishiro M, Jung HY, Goda K et al. Desirable training and roles of Japanese endoscopists towards the further penetration of endoscopic submucosal dissection in Asia. Dig Endosc 2012; 24: $121-123$

139 Oda I, Odagaki T, Suzuki H et al. Learning curve for endoscopic submucosal dissection of early gastric cancer based on trainee experience. Dig Endosc 2012; 24: 129-132

140 Yamamoto S, Uedo N, Ishihara R et al. Endoscopic submucosal dissection for early gastric cancer performed by supervised residents: assessment of feasibility and learning curve. Endoscopy 2009; 41: 923 -928

141 Niimi K, Fujishiro M, Goto $O$ et al. Safety and efficacy of colorectal endoscopic submucosal dissection by the trainee endoscopists. Dig Endosc 2012; 24: 154-158

142 Yamamoto $Y$, Fujisaki J, Ishiyama A et al. Current status of training for endoscopic submucosal dissection for gastric epithelial neoplasm at Cancer Institute Hospital, Japanese Foundation for Cancer Research, a famous Japanese hospital. Dig Endosc 2012; 24: $148-153$

143 Neuhaus H. Endoscopic submucosal dissection in the upper gastrointestinal tract: present and future view of Europe. Dig Endosc 2009; 21: 4-6

144 Dinis-Ribeiro M, Pimentel-Nunes P, Afonso $M$ et al. A European case series of endoscopic submucosal dissection for gastric superficial lesions. Gastrointest Endosc 2009; 69: 350 - 355

145 Deprez PH, Bergman JJ, Meisner S et al. Current practice with endoscopic submucosal dissection in Europe: position statement from a panel of experts. Endoscopy 2010; 42: $853-858$

146 Farhat S, Chaussade S, Ponchon T et al. Endoscopic submucosal dissection in a European setting. A multi-institutional report of a technique in development. Endoscopy 2011; 43: 664-670

147 Toyonaga T, Man-i M, East JE et al. 1,635 Endoscopic submucosal dissection cases in the esophagus, stomach, and colorectum: complication rates and long-term outcomes. Surg Endosc 2013; 27: 1000-1008
148 Berr F, Ponchon T, Neureiter D et al. Experimental endoscopic submucosal dissection training in a porcine model: learning experience of skilled Western endoscopists. Dig Endosc 2011; 23: 281 - 289

149 Nicolas-Pérez D. Endoscopic submucosal dissection: only for expert endoscopists? Gastroenterol Hepatol 2012; 35: 344-367

150 Vázquez-Sequeiros E, de Miquel DB, Olcina $J R$ et al. Training model for teaching endoscopic submucosal dissection of gastric tumors. Rev Esp Enferm Dig 2009; 101: 546 552

151 Parra-Blanco A, Arnau MR, Nicolas-Perez D et al. Endoscopic submucosal dissection training with pig models in a Western country. World J Gastroenterol 2010; 16: 2895-2900

152 Gotoda T, Friedland S, Hamanaka $H$ et al. A learning curve for advanced endoscopic resection. Gastrointest Endosc 2005; 62: 866-867

153 Hon SS, Ng SS, Lee JF et al. In vitro porcine training model for colonic endoscopic submucosal dissection: an inexpensive and safe way to acquire a complex endoscopic technique. Surg Endosc 2010; 24: 24392443

154 Wang TE, Wang HY, Lin CC et al. Simulating a target lesion for endoscopic submucosal dissection training in an ex vivo pig model. Gastrointest Endosc 2011; 74: 398-402

155 Coda S, Trentino P, Antonellis $F$ et al. A Western single-center experience with endoscopic submucosal dissection for early gastrointestinal cancers. Gastric Cancer 2010; 13: $258-263$

\section{Bibliography}

Dol http://dx.doi.org/

10.1055/s-0034-136492

Endoscopy 2014; 46: 361

(c) Georg Thieme Verlag KG

Stuttgart · New York

ISSN 0013-726X

\section{Corresponding author}

Gloria Fernández-Esparrach, MD PhD

Endoscopy Unit

Service of Gastroenterology, ICMDM

Hospital Clínic

Villarroel 170

08036 Barcelona (Spain)

Phone: +34-932275513

Fax: +34-932279850

mgfernan@clinic.ub.es 